Journal of Qualitative Criminal Justice \& Criminology

\title{
Book Review | Qualitative Research in Criminology
}

\author{
Carl Root ${ }^{1}$ \\ ${ }^{1}$ Eastern Kentucky State
}

Published on: Aug 15, 2020

License: Creative Commons Attribution 4.0 International License (CC-BY 4.0). 
Jody Miller and Wilson R. Palacios (eds.). Qualitative Research in Criminology. Transaction Publishers, 2015; 363 pp.; ISBN: 9781412856775.

Qualitative Research in Criminology is Volume 20 in the series titled Advances in Criminological Theory edited by William S. Laufer and Freda Adler. The title of Miller and Palacios' contribution brings to mind the saying "one of these things is not like the others." In fact, they acknowledge as much on page three of the introduction, as they state, "For some readers, our strategy may beg the question, why does a volume oriented around methodology belong in a theoretical series?" Miller and Palacios give a brief answer to this question, but allow the seventeen chapters that comprise their volume to provide the best evidence for such inclusion.

The book is organized thematically into six parts: (a) Qualitative Criminology: History and Epistemology; (b) Narratives, Biography, and Cultural Meanings of Crime; (c) Positionality and the Study of Criminalized Social Worlds; (d) Comparative Social Organization of Place and Crime; (e) Understanding Punishment and Society; and (f) Long Views on Qualitative Criminology. Each part consists of three chapters with the exception of part four, which only has two. Prominent and respected criminologists who have contributed to theory through their own research share insight into their work and in so doing elucidate the myriad ways that qualitative research and criminological theory intertwine.

The first section creates the context for the rest of the book. Covering the history and epistemology of qualitative criminology are Dick Hobbs, Michael Agar and Peter K. Manning. Hobbs provides a brief history of qualitative research in criminology beginning with English journalist Henry Mayhew's work documenting the lives of London's working class. Hobbs quickly, but thoroughly, brings the reader through the Chicago School, the radicals of the 1960s and 1970s, and all the way up to the more recent "fierce critiques" by Loic Wacquant of the role of theory in influential ethnographies. Ultimately, he concludes that fieldwork, properly conducted, "offers the prospect of genuine theoretical innovation" (p. 29). Reflecting on his years conducting drug research, Michael Agar then explores the concept of "library shock," explaining how different addiction was from the mouths and minds of addicts compared to the descriptions and explanations in the academic literature. (As he says on p. 37, "The way most of it was written, I couldn't understand why they called it that.") At one point, he references the Frankfurt School's idea of science as preserving ideology and he concludes hoping that this will not continue to be the case for criminology. Finally, Manning describes the role that "cautious generalizations" from his fieldwork on policing played in the development of the dramaturgical perspective. The rest of the volume contains similar discussions on the interplay between theory and their qualitative research. 
Part II provides three chapters detailing how the collection of narrative accounts of crime and criminal justice can provide theoretical insight. Sharing observations about the case of 18 -year-old "Jez," Gadd and Corr detail how psychosocial criminology can use in-depth interview and case studies to help make sense of senseless violence. Likewise, Presser and Sandburg share samples from interviews with "Ola," "Don," and "Dwight" to illustrate the different ways that personal narrative can elucidate issues of agency and action as both relate to crime. The section concludes with Fleisher's description of how allowing prisoners the opportunity to educate researchers on inmate argot provided understanding of the cultural meaning of prison rape.

Part III includes three essays on the relevance of researcher identity in qualitative research and theory development. In particular, the essays discussed how this identity provides understanding of a phenomenon through both prior knowledge and exposure (or the lack thereof). First, Bucerius describes how her position as an "outsider" studying male Muslim drugdealers in Germany offered distinct advantages, contrary to conventional wisdom. Then, Contreras provides the opposite perspective pointing out how his insider status granted increased access in understanding "stickup kids" in the Bronx. This section concludes with Panfil's research on queer criminology and how her identity provided access, but also how her attempt to avoid certain common assumptions about LGBTQ people almost cost her important insight.

Part IV is the shortest of the sections, containing one fewer chapter than the others. This is likely due to the loss of several contributors, which the editors mention in their introduction. Still, the two chapters provide compelling arguments for expanding the scope of qualitative criminological research beyond its traditional geographic borders. Arias uses research in the shantytowns of Brazil to describe how ethnography, participant observation, and interviews can contribute to a comparative criminology that could likewise open some of the discipline's traditional theoretical borders for further exploration. Zhang and Chin similarly explain the important role that qualitative research played in their development of a "cartwheel network theory" as an alternative to the dominant narratives of Chinese criminal organizations as the primary culprits of human smuggling.

Part V, on understanding punishment and society, includes contributions from Haney, Liebling, and Lynch on how the connections between qualitative research and theory pertain to studies of corrections. Haney argues for ethnography going beyond thick description to theoretical reconstruction by initiating conversation between the punished and theorists of punishment while describing her own prison ethnography. Liebling describes how such an approach can be greatly aided by considering the types of questions we ask and particularly advocating for appreciative inquiry. Finally, Lynch illustrates how found objects and documents can facilitate another kind of theoretically rich conversation regarding punishment. 
The last section of the book is titled "Long Views on Qualitative Criminology" and begins with a chapter by Ferrell on the promise and prospect of cultural criminology as both method and theory. This is followed by Maruna's argument for qualitative research within an evaluation of what works in criminal justice and a sort of "state of the union" of criminology and qualitative research by Wright, Jacques and Stein. As with the rest of the book, these perspectives span a broad epistemological continuum related to current issues in qualitative research as well as future goals and how to achieve them. The final chapter concludes with a call for a more inclusive criminology where the dichotomy of quants vs. quals can be overcome with collaboration, data sharing, and a broadened lens that looks outside of traditionally studied populations and issues.

Overall the book does a fine job of providing a breadth and depth of perspectives related to qualitative research in criminology and how such research pertains to advances in theory. Specifically, the collection taken as a whole gives the reader the distinct impression that qualitative research is crucial regarding both the development and the refining of criminological theories. A variety of opinions are included related to how qualitative research might garner the respect and resources it deserves in the often restrictive confines of a criminology currently dominated by quantitative research. There are likewise a variety of different approaches to qualitative research, almost as many as there are chapters in this book. Field research, ethnography, interviews, content analysis, narrative, discourse analysis, and other options available to the qualitative researcher are all given consideration. Contributors provide considerable insight into how data collection and analysis in these different types of qualitative research are both informed by and informative to theoretical perspectives. As such this text is a welcome addition to the qualitative researchers' library and would be a worthwhile reader for incorporation into both courses on theory and methods. It would be particularly necessary in those few programs where qualitative methods are a required part of the curriculum, but just as useful in those where qualitative research continues to remain an elective option. 